\section{Conclusion}

In Pakistan, the national annual budget for mental health is far below what would be necessary to meet the needs of the population. There are very few child mental health facilities in the country (Syed et al, 2007b).

Collaborative working between professionals managing children needs to be strengthened. Management guidelines have to be developed, as this will enable good clinical care and also facilitate research and audit. Research is needed to identify the prevalence, psychopathology and needs of mental health problems in children and priorities for management. Psychiatrists trained abroad could be a source of support and training, preferably on a longer-term basis, through email consultation and supervision. The transfer of skills through workshops and short training courses also is effective.

Children lacking in mental health have an adverse effect on the country's productivity, economic stability and viability. Recent research from Karachi, Pakistan, has highlighted effective models of utilisation of scarce child mental health resources within the current health and educational setup (Syed et al, 2007b). Policy-makers in the face of lack of finances and resources need to make decisions based on the efficacy of proposed and evaluated interventions which are not only beneficial to the population in question but also cost-effective.

\section{Acknowledgements}

The authors would like to thank Dr Amina Tareen, Consultant Child and Adolescent Psychiatrist (London, UK), for her expert comments and support in the writing of this paper.

\section{References}

Fayyad, J. A., Jahshan, C. S. \& Karam, E. G. (2001) Systems development of child mental health services in developing countries. Child and Adolescent Psychiatric Clinics of North America, 10, 745-762.

Gadit, A. A. (2007) Comparison between a developed and a developing country. Journal of Medical and Biological Sciences, 1, 1-7.

Nikapota, D. A. (1991) Child psychiatry in developing countries. British Journal of Psychiatry, 158, 743-751.

Park, K. M-E. (2002) Up to one fifth of the world's children has mental or behavioral problems. UN Chronicle, June-August. See http://www. un.org.pk/gmc/chronicle-bah-prob.htm (last accessed August 2008).

Rahman, A., Mubbashar, M., Harrington, R., et al (2000) Annotation. Developing child mental health services in developing countries. Journal of Child Psychology and Psychiatry and Allied Disciplines, 41, 539-546.

Rahman, A., Nizami, A., Minhas, A., et al (2006) E-mental health in Pakistan: a pilot study of training and supervision in child psychiatry using the internet. Psychiatric Bulletin, 30, 149-152.

Sherer, R. (2002) Mental health care in the developing world. Psychiatric Times, 19(1).

Syed, E. U., Hussein, S. A. \& Mahmud, S. (2007a) Screening for emotional and behavioural problems amongst 5-11-year-old school children in Karachi, Pakistan. Social Psychiatry and Psychiatric Epidemiology, 42, 421-427.

Syed, E. U., Hussein, S. A. \& Yousafzai, A. W. (2007b) Developing services with limited resources: establishing a CAMHS in Pakistan. Child and Adolescent Mental Health, 12, 121-124.

\title{
Psychiatry in Belgium
}

\section{Benjamin J. Baig ${ }^{1}$ and Veronique Delvenne ${ }^{2}$}

${ }^{1}$ Clinical Lecturer in Psychiatry, Division of Psychiatry, University of Edinburgh, Royal Edinburgh Hospital, Edinburgh EH10 5HF, UK, email bbaig@staffmail.ed.ac.uk

${ }^{2}$ Vice-Présidente, Société Belge Francophone de Psychiatrie et des Disciplines Associées de l'Enfance et de l'Adolescence, Professor of Child and Adolescent Psychiatry, Free University of Brussels, Espace Thérapeutique Enfants-Adolescents-Parents, 24 Rue Ketels, 1020 Brussels, Belgium, email v.delvenne@skynet.be

$$
T_{\mathrm{n}}^{\mathrm{he}}
$$
he Kingdom of Belgium is a high-income country in northern Europe with an approximate area of $33000 \mathrm{~km}^{2}$ and a population of 10.5 million. The proportion of the population under the age of 15 years is $17 \%$ and the proportion of the population above the age of 60 years is $22 \%$. Life expectancy at birth is 75.2 years for males and 81.5 years for females. As a founding member of what is now the European Union, it hosts the headquarters of the European Commission and the European Parliament, as well as other major organisations, including NATO.

Belgium is divided into the Flemish-speaking region of Flanders, in the north, with $58 \%$ of the population, the French-speaking southern region of Wallonia, inhabited by $32 \%$, and the Brussels capital region, officially bilingual, inhabited by $10 \%$ of the population. A small German-speaking community exists in eastern Wallonia. Belgium's linguistic diversity is reflected in the organisation of its psychiatric institutions and legislation.

\section{Mental health policy}

In Belgium, as both federal government and communities are in charge of different parts of the mental health service, there is both a national mental health policy, formulated in 1988 , and a community mental health policy. A substance misuse policy is present which was initially formulated in 1921 and a national mental health programme was formulated in 1990 and updated in 1999.

Belgium has a suicide prevention policy, implemented by the Mental Health Centre in Brussels. It focuses on the quality of help offered and on the efficacy of the services from the 
network of providers in mental health and social care. The goals of the policy are: to optimise the care offered to clients at risk of suicidal behaviour; to develop networks to enable follow-up with at-risk patients; to lend support to and to share relevant knowledge with other carers; and to advocate for suicide prevention within local networks.

Belgium has a nationwide data-collection system or epidemiological study on mental health, known as the Minimum Psychiatric Dataset. There are specific programmes for mental health for minorities, refugees, disaster-affected populations, indigenous populations, the elderly and children.

Different organisations subsidised by public authorities exist in Wallonia, Brussels and Flanders. In the not-for-profit sector, organisations include the Wallonia Institute for Mental Health and the Brussels Francophone League for Mental Health. Their objectives are to join the representatives in the field of mental health (via their organisations) with stakeholders, including service users and carers, to regularly evaluate social mental health issues, to encourage critique of mental health practice, to participate in mental health promotion and to work on ethical questions.

There exist 'platforms' of dialogue which group together psychiatric care structures for each region. Their objective is to highlight the study of health service research needs and to open dialogue between the stakeholders in mental health to improve the availability of care.

Belgium has disability benefits for persons with mental disorders. Factors such as degree of autonomy in daily activities, ability to work and degree of handicap are assessed.

\section{Mental health services}

Belgium spends $6 \%$ of the total health budget on mental health. There are some 69 psychiatric hospitals in Belgium, with 22.1 psychiatric beds per 10000 population. There are around 18 psychiatrists per 100000 population. The primary sources of mental health financing are social insurance, private insurance, out-of-pocket expenditure by the patient or family, and tax-based revenue. The Flemishspeaking and French-speaking communities are in charge of all non-hospital mental healthcare, such as sheltered housing and centres for mental health. The federal government is in charge of hospitals, location of psychiatric care and quality of hospital care. Mental health is a part of the primary healthcare system and so the treatment of severe mental disorders is available at the primary care level. There is regular training in mental health for primary care professionals. Emergency facilities are geographically sectorised across the country, which offers immediate care at low rates, through subsidisation by the local centres.

Patients may also use regional ambulatory centres for a consultation or receive a home visit. Care is offered by a multidisciplinary team able to address the medical, psychiatric, psychological and social aspects of a health problem. The remit of mental healthcare centres is both curative and preventive.

Belgium has a long history of community care. The city of Geel is known for the early adoption of deinstitutionalisation. The earliest Geel infirmary and the model where patients go into town, interact with the community during the day, and return to the hospital at night date from the 13th century. This practice is based on the positive effects that placement in a host family gives. The model continues today, where patients participate in family life and sleep in the family house, but are still considered the responsibility of the hospital; they spend part of the day or all day in hospital doing various activities and can go back to the hospital for observation or in case of crisis. In 2003, there were 770 family accommodation places available in the Flemish region and 192 in the Walloon region.

\section{Mental health legislation}

The royal decision of May 2000 changing the previous one of 1976 fixed a maximum number of beds in psychiatric services. There are specific child and adolescent psychiatric beds in general, paediatric and psychiatric hospitals in Belgium. Since 2002 there have been specific legislative guidelines for child and adolescent psychiatric disorders. The latest legislation was enacted in 2000 and a new piece of legislation regarding the detention of those with a mental disorder was adopted in April 2007. Mental health legislation is uniform across both the Flemish and Wallonia regions.

\section{Research}

Belgium is cited as being in the top ten leading countries for psychiatric research, in terms of both the number of papers and impact. Funding has come primarily from the federal government and European Union framework programmes.

The Department of Psychiatry at Université Libre de Bruxelles, Erasme Hospital, has been involved in initiating and implementing large European consortia (e.g. the GENDEP Consortium) on the genetics of mood disorders and schizophrenia. A European network of clinical and research centres for genetic studies in mood disorders (Biomed I and Biomed II programmes) has been established. The department is now coordinating a European multicentre study on treatment-resistant depression, including prospective work on pharmacogenetics.

Other major research centres include: the Psychoneuroendocrinology Unit, University of Liege, which specialises in affective disorders; the Universitair Centrum Kinder- en Jeugdpsychiatrie, University Hospital, Antwerp, which specialises in child psychiatry; and the University Hospital Brugman, Brussels, which specialises in sleep medicine. The Unit for Suicide Research, University of Gent, studies the epidemiology of suicidal behaviour, the biological and psychological characteristics of suicidal behaviour and prevention strategies.

Pharmaceutical research in Belgium has been led by Janssen and Janssen-Cilag, and resulted in the development of both haloperidol in 1958 and risperidone in 1984.

\section{Education and training}

Belgium has nine medical schools; the oldest, the University of Leuven, dates from the 14th century. Most Belgian undergraduate training takes the form of a 3-year bachelor's degree, encompassing basic sciences, followed by a 4-year masters degree, which includes clinical disciplines. Psychiatry, 
medical psychology and child and adolescent psychiatry are included during the medical curriculum in the 7 years of study by Belgian medical graduates. They are also trained in aspects of the patient-doctor relationship during small-group sessions.

Postgraduate training and specialisation last 5 years, during which trainees work under the supervision of a 'maitre de stage' in adult psychiatry, as well as child and adolescent psychiatry, and they also spend 1 year in neurology, paediatrics or internal medicine.

One year of training can be done in research. At the end of the specialisation, the candidate must publish one paper in an international journal or present at an international conference. Training includes mandatory academic courses and an examination during the third year. Since 2002, specific training in child and adolescent psychiatry has been available. Following specialisation, trainees will have a specific registration number from the Institut National d'Assurance Maladie-Invalidité (National Institute of Illness and Disability Insurance).

\section{Psychiatric associations}

Psychiatric associations in Belgium are divided between adult and child disciplines, and French-speaking and Flemishspeaking organisations. The primary association is the Société Royale de Médecine Mentale de Belgique (Royal Society of Mental Medicine of Belgium), which was founded in 1869. It is responsible for the primary Belgian psychiatric journal, the Acta Psychiatrica Belgica. The Vlaamse Vereniging Voor Psychiatrie (Flemish Association of Psychiatry) represents the Flemish-speaking community of adult psychiatrists. The Société Belge Francophone de Psychiatrie et des Disciplines Associées de I'Enfance et de l'Adolescence (French Belgian Society of Psychiatry and Associated Disciplines of Childhood and Adolescence) represents the French-speaking child and adolescent mental health professionals and the De Vlaamse Vereniging voor Kinder- en Jeugdpsychiatrie is the Flemish equivalent.

These professional societies are responsible for specialist professional standards, education and providing advice on policy. They are responsible for mental health promotion and the organisation of scientific events and congresses each year.

The Belgian College of Neuropsychopharmacology and Biological Psychiatry (BCNBP) was founded in 1974 and represents the scientific body of psychiatrists in Belgium.

\section{Conclusion}

As a high-income European country, Belgium has a modern psychiatric infrastructure comprising policy, legislation, community care, education, training and research. The integration of policy and services may be limited by its linguistic and cultural diversity, and future care programmes and pathways may benefit from a more unified strategy. Community care has historically been seen as a priority and the legislation in 2000 supports this continuing trend.

\section{Sources}

Andriessen, K., Clara, A. \& Beuckx, K. (2002) The suicide prevention policy of a mental health centre. International Journal of Mental Health Promotion, 4, 20-23.

Baro F., Prims A. \& de Schouwer, P. (1984) Belgium: psychiatric care in a pluralist system. In Mental Health Care in the European Community (ed. S. P. Mangen), pp. 42-54. Croom Helm.

Der Minister van Consumentenzaken, Volksgezondheid en Leefmilieu and Aelvoet, M. (2000) Legislation Concerning Mental Health. Federale databank van de beoefenaars van de gezondheidszorgberoepen, Public Federal Service of Health, Food Chain Safety and Environment, January, 2004

Fava, G. A \& Ottolini, F. (2004) International trends in psychiatric research. A citation analysis. Services research and outcomes. Current Opinion in Psychiatry, 17, 283-287.

Simoens-Desmet, A. (1998) Rapport National 1998 du Resume Psychiatrique Minimum. Ministere des Affaires Sociale, Se la Santè, Publique et de l'Environment.

Van Heeringen, K. (2003) Unit for Suicide Research, University of Gent, Belgium. British Journal of Psychiatry, 183, 260-261.

World Health Organization (2005) Belgium. In Mental Health Atlas 2005. See http://www.who.int/globalatlas/default.asp (last accessed August 2008).

\section{Mental health in Yemen: obstacles and challenges}

\section{Maan A. Bari Qasem Saleh PhD ${ }^{1}$ and Ahmed Mohamed Makki MD}

${ }^{1}$ Associate Professor, Faculty of Medicine, Aden University, Yemen, email maanymha@yahoo.com ${ }^{2}$ Reporter, Health Committee, Shura Council, Past Deputy Minister of Health

\begin{abstract}
The Republic of Yemen, on the south-western coast of the Arabian Peninsula, was formed in 1990 when North and South Yemen united. Yemen covers $527970 \mathrm{~km}^{2}$. The capital is Sana'a. The country is divided into 20 governorates and one municipality. It has an elected president, an elected House of Representatives, and an appointed Shura Council. The president is head of state, and the prime minister is head of government. Suffrage is universal for
\end{abstract}

people aged 18 and older. The population of Yemen according to the 2004 census is about 20 million, but recent years have seen the arrival of many refugees.

Mental health in Yemen has been fortunate to receive government support, albeit modest, and benefits from human resource development projects. These projects have enabled Yemeni students to study psychiatry, psychology, psychiatric nursing and social work abroad. Mental health in 